\title{
Finding disturbances in on-farm biogas production
}

\author{
Pereira-Querol Marco Antonio ${ }^{\mathrm{a}}$ and Seppänen Laura ${ }^{\mathrm{b}}$ \\ ${ }^{a}$ Center of Research on Activity and Learning, Institute of Behavioural Sciences, P.O. Box 9, FIN-00014 Tel. +358 \\ 50 4156637, E-mail: mapquero@gmail.com, University of Helsinki, Finland \\ ${ }^{\mathrm{b}}$ The Finnish Institute of Occupational Health, Topeliuksenkatu 41 A, FI-00250 Helsinki, Finland
}

\begin{abstract}
When implementing innovations, disturbances are very likely to take place. Disturbances are undesirable because they can lead to unwanted outcomes, such as economic losses and work overload to workers. However, they can be powerful opportunities for learning and re-designing innovations. Here, we will present activity theoretical tools for analyzing disturbances in a way that they could be used as learning opportunities. We illustrate the proposed tools by analyzing a disturbance that took place during the implementation of a project of biogas production. By interpreting the disturbance process with a network of activity systems, we found that on-farm disturbances were formed as ruptures, innovations and asynchronies originated in other activity systems. This finding suggests that disturbances are outcomes of the functioning of networks, rather than simple results of failure of individuals or technical devices. The proposed tools could be used in interventions to help practitioners and ergonomists to recognize the systemic and networked nature of problems, and therefore, realize that they may require the collaboration of actors from different activities. In this sense, disturbances may be turned into opportunities for learning and developing innovations. We conclude by discussing how the method could be used in ergonomic design and intervention.
\end{abstract}

Keywords: disturbances, learning, biogas production, activity theory

\section{Introduction}

Consider the following example of a complex process taking place during the implementation of an innovative program for sustainable swine production in Brazil:

A food industry was implementing bio-digesters for on-farm biogas production for supporting their outsourced farms to become more sustainable. As the program was implemented some disturbances started to emerge, e.g.: rusting, leakage of gas. The rusting and the leakage of gas were related to many factors or events. Farmers blamed engineers and assembling companies for not properly instructing them or not properly installing the equipment. Engineers blamed farmers for not taking basic maintenance operations, and the high administration of the company for not responding quickly to requests, e.g.: hiring a maintenance company. The high administration blamed the UNFCCC executive board for changing the procedure for applying for carbon credits, which was leading to considerable delays and asynchronies. How can managers, engineers, technicians and farmers learn to work in such a way that the new environmental and social needs are met and the economic costs are paid?

In the example there were many possible interpretations of the causes of the rusting and leakage and how they could be solved. Usual interpretations are that they were caused by technical inadequacy or individual behaviour. This interpretation may be correct, but could it help actors to deal with the root causes of the disturbance? Rusting and leakage has been pointed as problems in biogas production (BP) already since the early projects during the 1970's. How could these disturbances be used so that we could make biogas production more sustainable?

The disturbances presented above bring up several aspects of biogas production system. First, BP involved several activities outside the farm suggesting 
that an effective re-solution of disturbances would require the involvement not only of farmers and engineers but also of actors from other activities. Second, there is a diversity of perspectives of the actors, who gave technological, communicational, and economic reasons for the disturbance. All the explanations seem to be (partially) valid. Third, the technical, organisational and financial factors were interconnected, and call for a resolution at the level of a system rather than on the level of individual actors. The problem is how to create such a solution when there is no one actor who ought to or could create it. This leads us to the question of how to understand these disturbances so that they can be effectively solved, and the system made to work.

Although the disturbances of rusting and leakage were not threatening the biogas production, and they could be fixed relatively easily; they can play an important role in reflecting other major problems in biogas production, and may be used as a mirror for further developing the system. In order to do this, we propose tools for analysing disturbances in a way that allows for the visualization of the nature of the problem and ways to go further. In this paper we see disturbances as opportunities for learning and development rather than seeing them as something negative to be avoided. We present theoretical and analytical concepts based on an activity theoretical interpretation of disturbances processes. In this approach disturbances are interpreted as expression or manifestation of contradictions inherent or intrinsic to a system. The paper starts by presenting our case of $\mathrm{BP}$ and introducing several theoretical concepts. We continue presenting the methods and data. We exemplify the analysis by referring to an observed disturbance in a network. The analysis enables us to understand 'designers' and 'decision makers' activities (3). Finally, the paper ends with a discussion about the advantages and limitations of the presented tools.

\section{Sadia's Program of sustainable swine production}

\subsection{The 3 S program}

Since the end of the 1990s in the south-west region of the state of Santa Catarina (SC), Brazil, there has been increasing pressure on the part of local communities demanding farmers and the food industry to deal more effectively with the problem of the polluted local water supplies caused by swine production. Parallel to this, Sadia food company, started three Clean Development Mechanism (CDM) projects of BP in its own farms. In 2003, while writing a Project Design Document (PDD) in the application process for carbon credits, the engineers came up with the idea of using the CDM from the Kyoto Protocol, which would allow the farms of the outsourced farmers to be adjusted to the environmental legislation. In the first semester of 2004, Sadia started the design of the Program. In December 2004, the Sadia Institute (SI) was created to implement BP among its outsourced farms.

At the beginning of 2005 Sadia announced the emergence of the $3 \mathrm{~S}$ Program, aimed to promote the sustainable development of swine production. Sustainability was understood in the program as the use of resources to satisfy the needs of the present without compromising the needs of future generations.

The idea of the 3S Program was to implement CDM projects in the company's outsourced farms through the implementation of bio-digesters. These would be used to manage and treat swine manure and reduce GHG emissions. The SI borrowed money from a financial institution for purchasing and installing the bio-digesters and the combustion system in the outsourced farms. The SI would coordinate the implementation and maintenance of the bio-digesters, while the farmers would operate the bio-digesters leased to them by the SI, paying back the investment with carbon credits. The institute would negotiate the carbon credits on the carbon market, and the carbon revenue obtained would be used to cover the biodigester installation and operational costs of the program. The resulting surplus would be used to improve the social and environmental conditions of the participating farmers. Until May 2008, the 3S Program was implemented in the states in which Sadia operated, Santa Catarina, Paraná, Rio Grande do Sul, Mato Grosso and Minas Gerais.

\subsection{Historical contradictions in the concept of BP in the $3 S$ Program}

A recent study has analysed the historical contradictions and developmental phases of BP in the $3 \mathrm{~S}$ Program $(10,11)$. These studies propose that BP was part of Sadia's attempt to deal with environmental problems arising from by swine production. Sadia was in the phase of application of its new concept of swine production through the $3 \mathrm{~S}$ Program. In the new concept, swine production included the control of the environmental and social impact of swine production. In this new concept, BP 
was a technical and financial instrument for making swine production sustainable.

The new concept of BP was intended to obtain of carbon credits by means of biogas and had been intended for local use and more specifically for investing in and improving both environmental management aspects as well as the quality of life of farmers. However, in practice, the abovementioned good intentions have turned out to have unintended, even problematic, results. The production of carbon credits required equipment of such a high degree of sophistication that it undermined the capacity to farmers to use the gas locally. Moreover, the increase in the cost of the project led to the exclusion of the smallest and poorest farmers. This paradox became aggravated with the new UNFCCC methodology, which required an even more sophisticated and expensive burning and measuring system. Thus, the production of carbon credits and the local use of the gas seemed to be contradictory. In this study, we hypothesize that this contradiction was leading to the emergence of disturbances related to the motivation of farmers to do operations to maximise BP.

\section{Cultural-historical activity theoretical approach}

In organizations, problems are seen as negative events, which are usually ignored or avoided. In innovation studies problems are acknowledged as important forces for development. Disturbances can be used as opportunities to increase the sense of urgency for change and to focus learning actions (14). Changes in technological systems are usually precipitated either by problems taking place at the present or there are problems that are predicted to take place in certain conditions (2). Problems have been interpreted in several ways, such as systemic failures (15), tensions, misfits (8). Among those interpretations, problems can either be seen as obstacles to be solved or as opportunities for promoting learning.

In this study, disturbances are seen as expressions of contradictions inner to a certain system. Becoming conscious about these contradictions can play an important role in developing such system.
3.1. Network of activity systems as unit of analysisIn an activity theoretical approach in order to analyse problems, an activity system or a network of activity systems is taken as a minimum unit of analysis (5). An activity system depicts not only the tools and signs, but also the social organisational mediators, such as rules, division of labour and community (Figure 1). The community refers to those who take part in realising the object, the rules refer to explicit norms and conventions that constrain action within the activity system; and the division of labour refers to the division of tasks among the individuals of the community. Activity systems are never isolated, but always affecting and being affected each other (4).

Contradictions may have several meanings in different theoretical approaches. In activity theory, they are understood as historically evolving tensions that can be detected and dealt with in real activity systems. They are considered to be the driving force of transformation. Disturbances, dilemmas and conflicts are not the same as contradictions, but rather their expression.

\subsection{Disturbance process}

In order to identify a set of typical disturbance processes, and the contradictions behind them, we make use of four analytical concepts: disturbance, rupture, innovation and asynchrony. These concepts describe different kinds of deviations from the coordinated flow of actors' complementary actions, proposed in scripts and plans of the activity. These concepts have been mainly used in identifying problems in discursive interaction in work process. In this paper, the concepts are adapted to make them a tool for analysing problems in production processes. The general idea of disturbance is that it constitutes an interruption of the flow of work, or break in the logical process of bringing up an output.

In this paper, disturbance means a visible, undesirable, and unexpected event that is taking place in the process of producing biogas. Disturbance has undesirable consequences, which are directly related to a specific space and time. It means that they can be observed by actors. It is an event that was not expected by anybody, or a blockage of actions. In a technological system, it can be seen as an observable malfunctioning of a machine that endangers the attainment of the expected outcome. An example of a disturbance is the malfunctioning of a combustion system. This disturbance was observable: the gas was not burning and undesirable (because the gas was expected to burn). 
A rupture is a discoordination of actions, or a lack of an expected action that has caused or has the potential to cause future disturbances. The lack of action is something that can be observed in the latent reality, and therefore is rather objective. A rupture is a break in a chain of actions, which may be caused by a break in the flow of communication, miscommunication or misunderstandings. For example, a rupture may be an event in which a farmer had not removed the branch beside the bio-digester, a task that engineers expected them to do.

An asynchrony is understood as a situation in which part of the elements of the activity has been changed but the other part not, making the use of the elements impossible. An asynchrony may be experienced as a delay, a lack of a planned action. An asynchrony is very much related to the temporal dimension in which actions are taken. In other words, it takes place when a planned action is not taken, and some parts of the system falls behind causing disturbances. In contrast to ruptures, asynchronies mean a lack of action but can be seen in relation to plans of implementation rather than in relation to routine or operations (as it is the in ruptures).

An innovation is understood as an intentional unexpected action aimed to produce something that goes beyond what is established in the script. An innovation is temporally connected with disturbances and ruptures. Innovations may be created to solve disturbances and ruptures.

The concepts of disturbance, rupture, asynchrony and innovation are temporally related forming a chain. The chain of disturbances, ruptures, asynchronies and innovations which lead to the emergence of a certain disturbance, is called here as disturbance process. These disturbance processes are interpreted and located in a model of the network of activity systems to identify the activities involved in the process of disturbance, and therefore, the activities that would have to be involved in their solution. Such knowledge may indicate who and what should be done to further develop the network of activities involved in biogas production.

\section{Data and method}

\subsection{Data}

In this paper, we conduct an analysis of some disturbance processes observed during the farm visits that were taking place in the project of biogas production (BP) in the $3 \mathrm{~S}$ Program. The data used in the analysis of disturbances could be divided in three types: observed data, reported data (things that people say before, during or after the farm visits), and hypothetical data. The observed data were those in which the researcher witnessed what was going on. Data includes field-notes, photos, operating documents such as functional documents used by actors in their everyday work (guidelines, design reports and plans), and video-recorded farm visits, in which we observed the practices in the everyday work of the actors. One example of observed data is that the researcher (the first author) saw a farmer touching the flare. The reported data were composed by those in which other people reported what had happened (historical events and actions). They consist of interviews, informal conversations, audio-video recorded interactions between actors and reporting documents such as news and reports made by technicians. One example of reported data is a report saying that a farmer had touched the flare, or that somebody tells me in an interview that a farmer had touched the flare. The hypothetical data comprises data in which actors attempt to explain what happens. They consist of interviews, informal conversations, documents (e.g.: news and studies). Thus, they are interpretations and explanations given by people. One example of hypothetical data is an explanation given by somebody of why a farmer touches a flare.

\subsection{The method of data analysis}

The analysis starts from disturbances that could be observed disturbances during the farm visits from May 2008. It proceeds by reconstructing the disturbance process by analysing the explanation given by people about the observed events. The explanations are interpreted with the analytical concepts and located at the level of network of activity systems.

The first step was to identify the disturbances, ruptures and innovations that took place during the farm visit in May 2008. At this stage, we were interested in those disturbances that were taking place during the farm visits. The process started by reading through the transcribed farm visit. To identify them, we had some knowledge in advance on how the technological system was supposed to be working. This knowledge was obtained through operational documents (guidelines or the project design), as well as interviews with engineers and farmers. These documents made explicit what actors were supposed to do, and how the technological equipment was supposed to be operating. We only considered events 
observed and mentioned by the people present during the farm visit (e.g. farmers, the SI's engineers) as a disturbance. Once identified, these events were classified according to which part of the equipment they were related to, while the ruptures were related to what kind of disturbance it could generate.

After the disturbances had been identified, explanations and evidences about them were collected. These explanations were given either during the farm visits or in other circumstances such as during a visit to another farm or during a conversation in the office. The explanations were either specifically about the disturbances and ruptures observed during the visits to the farms, or about the kind of disturbance in general. Such reported disturbances, ruptures and innovations are introduced in their disturbance processes.

Once a list of disturbances and ruptures that took place during the farm visit was made, we selected several disturbances in order to further describe the process by which they were formed. The main criteria for selection were sufficient explanations and empirical evidence. These events were employed for writing a logical chain of actions (or lack of it) that led to the disturbances. This chain of actions of a disturbance is called a 'disturbance processes'. The disturbance process was modelled using a network of activity systems. The disturbances, ruptures and innovations were located in the model for each disturbance process.

\section{Findings}

In total, 17 disturbances, 18 ruptures and 2 innovations were observed during the visits to the farms. Several other innovations which took place either in the past or in other farms (than those visited) were mentioned. Those innovations are not included here, but instead they are explored when they are considered to have a causal relationship with the observed disturbances. The disturbances, ruptures and innovations were classified according to their consequence to the functioning of the technological system. Six types of disturbances have been identified: I) failure of the combustion system; II) underproduction of gas, and leakage of gas; III), rusting of metal parts of the bio-digester; IV) deterioration of the flare; V) obstruction of tubes; and VI) explosion of the balloon and other burning accidents.

Because of the limitation of space, we will present here only the case of leakage of gas and rusting of metal parts close to the security valve as examples of disturbances. The leakage of biogas was a problem for several actors of the activity. It was a problem for farmers because in addition to producing odour, the leakage of biogas also led to the rusting of metal parts of the system, increasing the maintenance costs (e.g.: replacing the door and the fences), and later to the replacement of the metal junction. For the SI (SI engineers and the financial administration of the program), the gas that leaked was not burned and in the future it might mean reducing the amount of carbon credits that could potentially be obtained, and consequently extending the time for paying back the loan obtained by the SI. Furthermore, the leaked gas went straight to the atmosphere contributing to global climate change, which the $3 \mathrm{~S}$ Program was aiming to mitigate. Despite these consequences, the leakage and rusting were not considered a serious disturbance for engineers and farmers, but this disturbance is interesting because it reveals some major ruptures in the implementation of the system.

\subsection{Description of the disturbance process of leakage and rusting of metal parts}

The most common place where rusting occurred, was in the area around the exit of gas from the security valve (disturbance). This owed to the fact that the burning system was installed only in 2008, while most of the bio-digesters were installed in 2006 and 2007. Without the burning system, the gas was released directly from the security valve leading to the rusting of the metal parts nearby. According to an engineer of the program, there were two main causes for the delay in the installation of the burning system (asynchrony). First, there was a change in the UNFCCC methodology (innovation), which in turn changed the rules about how one ought to account for carbon mitigated with an open flare. In the new methodology those projects using an open flare would be able to account only for $50 \%$ of the burned gas. Engineers had to develop a closed flare and a measuring system in order to keep the project viable and be able to request up to $90 \%$ of the methane burned as carbon credits. One problem was that the technologies available were adapted to large-scale production of biogas, and therefore, the equipment used for close flare and measuring was too expensive to be installed on a small farm. Thus, engineers had to develop new technologies for burning and measuring that could be adapted to small farms. The development of these technologies took several months, causing a delay in the implementation of the 
burning system in relation to the implementation of the bio-digester. The consequence was that during several months, and in some cases even years, the gas was released directly from the security valve into the air, rusting the fences and other metal parts close to it.

The disturbance of rusting around the security valve was attributed to the delay in installing the combustion system. The delay owed to the lack of knowledge among engineers and planners about the burning technology that could be used to burn the gas for obtaining carbon credits; and the lack of readily economically accessible burning and measuring technologies. These limitations were caused by the breach of contract with the consultant company and the emergence of new UNFCCC rules, which requested closed flares and measuring technologies. The flare and measuring system available at the time was too expensive for small farms.

\subsection{Location of the disturbance process in the model of network of activity systems}

The network of activity systems involved in the disturbance process of rusting around the security valve is shown in Figure 1.

The disturbance process started already in 2006 from an innovation from UNFCCC, in which new rules were established concerning the amount of carbon credits that could be certified from open flare, making it uneconomical in small farms. This rule was in itself the outcome of a contradiction inner to the object of the UNFCCC, which the consultant called the "CDM paradox". On the one hand, the UNFCCC wanted to contribute to sustainable development in an unrestricted way, including as many small-scale projects as possible. On the other hand, UNFCC has to make rules that make sure that the GHG emissions get reduced, which in practice gets translated into expensive technologies which exclude small farmers. This is interpreted in the model as a contradiction inherent to the UNFCCC's object.

The new methodology entered in the activity of the 3S Program as a new rule, contradicting with the object of the activity: small-scale farms. These new rules were also in tension with the knowledge and technologies accessible to the program staff. The situation is interpreted as a secondary contradiction in the activity of management of the program between the new rules and the knowledge that food industry staff had about CDM and the closed flares, and a tertiary contradiction between the objectives of the management of the program and the equipment of measuring systems available in the market. As mentioned, the devices available in the market were uneconomical on the scale of the small farm. This situation is interpreted as a secondary contradiction between the existing tools (technical devices for burning and measuring) and the object (small-scale farms).

Parallel to the innovation of the rules, there were ruptures in the supply of knowledge about CDM and technologies that could be used. This rupture leaded to an asynchrony in the installation of the flares, which led to the rusting of metal parts, a disturbance that could be observed in the farms. Thus, the disturbance of rusting of metal parts around the security valve had roots in other activities than the swine production in farms in which the BP technological systems was installed.

The analysis of this apparently rather simple and insignificant disturbance (rusting of metal parts around the security valve) nicely shows the roots of the problem in the network, and the need for network level solutions for a sustainable BP. The central factors behind this disturbance were (a) a change in the UNFCCC methodology, (b) break in collaboration between the management of the project and the consultancy, and (c) the lack of adequate tool for burning and measuring.

\section{Discussion and final considerations}

The analysis showed that an important cause of the disturbances came from a change of the UNFCCC methodology. The new methodology required the acquisition of rather expensive equipment for measuring the gas burned, and required certified biogas-use technologies, that were more expensive than the locally adapted ones; undermining the possibility of using the gas. This finding supports the hypothesis that an important source of disturbances was related to a contradiction inherent to the concept of BP of sustainability applied in the case: the process for obtaining carbon credits was undermining the process of using the biogas locally. This finding suggests that the development of the BP system would involve developing the elements so that both the biogas could be used locally and traded. 

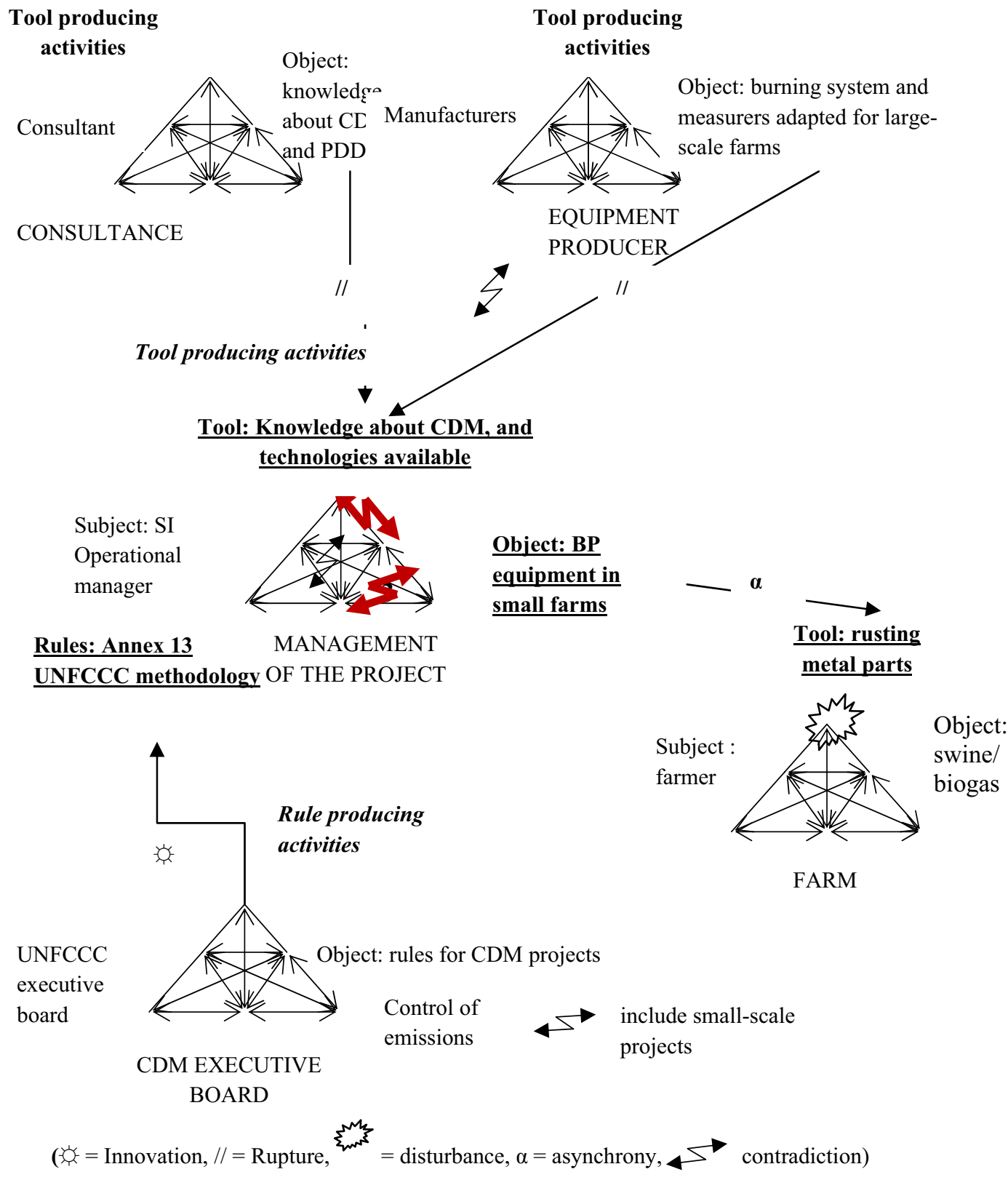

Fig. 1 Activity systems involved in the leakage and rusting from the security valve

The analysis produced some hypothesis of which elements in the systems are in tension, giving us some more concrete information of which elements must be developed: e.g. the new UNFCCC rule for burning and measuring the gas, the lack of knowledge about the CDM mechanisms, the expensive biogas-use technologies, and the disequilibrium between the volumes of bio-fertiliser produced and used within the farms. The elements that were facilitating the integration of BP for carbon credits to swine production seem to be the possibility of using the bio-fertiliser and the bio-digester for better manure management and to increase the volume of swine production as well as high energy need (the gas) for other farming activities.

The analysis shows that most of the disturbances that could be observed in the on-farm BP system are formed in other neighbouring activities, pointing to 
contradictions not only within and between elements of the on-farm BP system but also between other activities. This can be seen as an indication of tight coupling (12) between the activities in the BP network. The delay in obtaining carbon credits led to the delay in hiring maintenance, to the lack of motivation of farmers and to the rusting of the equipment. Because of the tight coupling between the elements of the BP system a change in one activity led to a chain of failures in other activities. This strongly suggests that in order to fully understand and solve disturbances expressed at the on-farm BP, we have to involve a network of activities.

A weakness of the proposed method of analysis and the theoretical approach used is that it requires the collection and analysis of longitudinal ethnographic data which is time-consuming. The results should not be seen as evidence, proof or facts, but rather as a hypothesis to be tested and further elaborated in future interventions. It can be used to help actors to expand their understanding of disturbances from narrow individual and technical explanations towards more systemic and historical ones. In this way, the analysis could move from a situation of blaming each other towards actions for changing specific elements of a system. In this way, the method could be used by interventionists to indirectly solve disturbances that compromise the efficiency of a system and substantially affect the well-being of workers $(9,13)$. Ergonomists also need to be aware of the possible risks that representing disturbances and contradictions may have in workplaces and networks (1).

The method of disturbance analysis proposed in this paper does not produce any change in itself. As any other tool, its power relies on its use by agents. In order to lead to changes in a system, it has to be used in interventions. If used for helping actors to visualize the key contradictions affecting their activities, the proposed method could allow actors to move from a contradictory layer of causality, in which actors search for solutions through unpredictable actions, to an agentive layer, in which actors take intentional agentive actions to change their activities $(6,7)$. In other words, the method could allow actors to get control over their activity and in this way to become agents of change for improving their work related well-being.

\section{References}

[1] P. Béguin, C. Owen and G. Wackers, Introduction: Shifting the focus to human work within complex socio-technical systems, in: Risky work environments. Reappraising human work within fallible systems, C. Owen, P. Béguin and G. Wackers, eds., Ashgate Publishing Ltd., 2009, pp. 1-10.

[2] E. W. Constant, Communities and hierarchies: structure in the practice of science and technology, in: The Mature of Technological Knowledge, R. Laudan, ed., Reidel, Dordrecht, 1984, pp. $27-46$.

[3] F. Daniellou, Design processes: managing continuity and discontinuity between present and future activity. Key note presented at the International Symposium Activity2008 Activity Analyses for Developing Work. Second Symposium of the Technical Committee 'Activity Theories for Work Analysis and Design' of the International Ergonomics Association (IEA). 2008.

[4] Y. Engeström, Learning by Expanding: An Activity Theoretical Approach to Developmental Research, Helsinki: Orienta Konsultit Oy, 1987.

[5] Y. Engeström, Activity theory as a framework for analyzing and redesigning work, Ergonomics 43 (2000), 960 -974.

[6] Y. Engeström, Development, movement and agency: breaking away into mycorrhizae activities, in: Building Activity Theory in Practice: Toward the Next Generation, K. Yamazumi, ed., CHAT Technical Reports 1. Kansai University Press, Osaka, 2006.

[7] Y. Engeström, From communities of practice to mycorrhizae, in: Communities of Practice: Critical Perspectives, J. Hughes, N. Jewson and L. Unwin, eds., London: Routledge, 2007, pp. 41-54.

[8] F. W. Geels, From sectoral systems of innovation to sociotechnical systems Insights about dynamics and change from sociology and institutional theory, Research Policy 33 (2004), 897-920.

[9] J. Mäkitalo, Work-related well-being in the transformation of nursing home work, Acta Universitatis Ouluensis D Medica 837, Ph.D. Dissertation, Oulu University, 2005.

[10] M. A. Pereira-Querol and L. Seppänen, Learning as changes in activity systems: the emergence of on-farm biogas production for carbon credits, Outlook on Agriculture 38(2009), 147-155.

[11] M. A. Pereira-Querol, Learning Challenges in Biogas Production for Sustainability: An activity theoretical study of a network from a swine industry chain. Ph.D. Dissertation, Helsinki University, 2011.

[12] C. Perrow, Normal Accidents: Living with High Risk Technologies. Perseus Books, 1984.

[13] L. Seppänen and A. Koli, Exploring work: Employee stories as tools for promoting workplace well-being, in: Proceedings of the International Conference Towards Better Work and Well-being, H. Anttonen, P. Husman, T. Hussi, T. Leino and M. Ylikoski, eds, Finnish Institute of Occupational Health, Helsinki, 2010

[14] B. van Mierlo, C. Leeuwis, R. Smits and R. Klein Woolthuis, Learning towards system innovation: evaluating a systemic instrument. Technological Forecasting and Social Change 77(2010), 318-334.

[15] R. K. Woolthuis, M. Lankhuizen, V. and Gilsing A, system failure framework for innovation policy design, Technovation 25(2005), 609-619. 